Printed Version: (ISSN 2090-5262)

Online Version: (ISSN 2090-5270)

March 2013, Volume 3, No. 1 Pages (78 - 87)

\title{
The Comparative Characteristic Indicators of the Kinematics of the Flèche Skill in Foil Fencing
}

\author{
Mahrousa Aly Hassan*, Sherifa Abdel-Hamid Afify**
}

* Assistant Professor, Curriculum and Physical Education Department, Faculty of Education, South Valley University

** Lecturer, Curriculum and Physical Education Department, Faculty of Education, Asyut University.

\begin{abstract}
This research aims at identifying the comparative characteristic indicators of the kinematics of the Flèche skill in foil fencing. The descriptive method was used, being suitable for this type of research. The study sample consisted of 2 fencers: 1 high-level fencer, and 1 under 15 years old ordinary fencer. Video shooting and kinematographic analysis were conducted on the kinematical variables (time - horizontal and vertical speeds of joints - speed achieved - angular speed and velocity of the body centre of gravity) in the main positions taken for analysis, including the on guard position, losing balance with the back foot leaving the floor, flying with the leading foot leaving the floor, landing (balance recovery). Results of the research showed an increase in the vertical speeds and velocities in the ordinary fencer, an undesirable increase because of the direction of the movement, and an increase in the horizontal speed in the high-level fencer. It is recommended to develop the kinematical variables that could help improve the performance level of fencers.
\end{abstract}

\section{Introduction and research problem}

tudying the ideal technical style in sports Sactivity greatly contributes to the improvement of performance and helps athletes exploit their potential and individual abilities to attain the highest levels of championship, while economizing efforts exerted. This is only possible through the conscious understanding of mechanic and technical foundations and components. According to Gamal Zaher (2007), success in winning fencing championships in international competitions depends on several physical and skillful factors which must be upgraded side by side to win championships and realize sport achievements. $(4-65)$.

Abbas El-Ramly (1981) (13) suggested that the analysis of skillful performance in fencing using cinematographic shooting and kinematographic analysis represents an important step in preparing the fencer and honing his/her skills when training for competition or championship. The Flèche skill is one of the major factors leading to winning competitions, because it involves the quick, surprising attack on the opponent using the weapon and the body together. It is used in all fencing schools and in two types of fencing: the foil and the sabre. The skill was officially abolished from the saber fencing in accordance with the amendment of the 1995 Law of the Egyptian Fencing Federation.

D. Gordon, E. Robertson, Graham Caldwell, Joseph Hamill and Sauders N. Whittleesy (2004) (14) stated that the Flèche is used when the opponent is far from the reach of the fencer with the aim of gaining time and distance. The skill requires speed, strong performance and choosing the appropriate time to touch the targeted point in the opponent's body. It is a skill to be mastered by the fencer for its genuine effect on the result of the game and because it helps the fencer control the fencing distance. To be successful, the Flèche depends on surprise and quick performance.

According to Gamal Abdin (1989) (5), Nancy (1989) (16), Mahrousa Aly Hassan (1999) (11), 
the Flèche skill can be divided into three phases as follows:

The preparatory phase, including:

- The on guard position

- The arm extending position, while stepping forward

- The main phase, including:

- Losing balance

- Flight

- Effecting the touch

The final phase, including:

- Balance recovery

- landing

A review of fencing international competitions played in the recent years as recorded on compact discs, with a view to tracking the Egyptian performance, showed a high level of technical performance in the teams of Germany, Hungary and Belgium compared to that of the Egyptian team. The former reflected speed, strong performance and high connectivity between skilful, technical and physical performances. Analysis of the Flèche skill as illustrated through replay of 102 matches, using the three techniques of display (slow, normal level and still), and excluding matches uncompleted due to injuries, proved that the teams of the three European countries used the Flèche skill more often, compared to Egyptian team. This was the underlying cause of conducting this study to identify the comparative distinctive indicators of the kinematics of the Flèche skill in foil fencing.

\section{Objective of the study}

Identifying the comparative distinctive indicators of the kinematics of the Flèche skill in foil fencing.

\section{Hypotheses}

There are differences in the comparative distinctive indicators of the kinematics of the Flèche skill in foil fencing between the following phases:

The on guard position

- Losing balance
- Flight

- Landing and recovery

\section{Research procedures}

\section{Methodology}

The descriptive method was used, being suitable for this type of research.

\section{Research sample}

The study sample was intentionally selected and consisted of 2 fencers classified as follows: 1 high-level fencer, and 1 under 15 years old ordinary fencer. Each fencer performed three Flèche movements. Fencers were selected according to the following criteria: registration in the records of Alexandria Fencing District; a period of practicing fencing no less than 5 years for the high-level fencer, and no less than 3 years for the normal level fencer under 15 years old. Distinctive indicators of the skill were analyzed to detect points of weakness.

\section{Research scopes}

\section{Time scope}

The study was conducted in the period 06/11/2009-08/01/2010

\section{Geographical scope}

\section{Alexandria Fencing Club}

\section{Data collecting tools}

\section{Videao-tapes}

The video clips were shot from a vertical level $\left(90^{\circ}\right)$, so that the fencer would be displayed in a size that is easy to analyze and the angle between fencer and lens covers performance limits.

\section{Kinematographic analysis}

The best successful of the three attempts by each fencer was chosen for analysis using the computer and analysis software. Analysis determined the major phases of the skill which were:

- the on guard position,

- losing balance with the back foot leaving the floor,

- flying with the leading foot leaving the floor,

- landing (balance recovery). 


\section{Kinematical variables}

The time for each phase and the total time taken;

The horizontal and vertical speeds of the fingers, the wrist, the elbow, the shoulder, the ankle, the knee and the thigh in each position taken for analysis;
The speed achieved, and the angular speed and velocity of the body centre of gravity in each position taken for analysis.

\section{Presentation of the study results}

Figure (1) the sketch of the Flèche skill in high level fencers

Figure (2) the sketch of the Flèche skill in normal level fencers

Table (1)

The time frame of the Flèche skill in high level and normal level fencers

\begin{tabular}{|l|l|l|}
\hline Skillful performance phases & High level fencer & Normal level fencer \\
\hline On guard position & .49 & .61 \\
\hline Losing balance & .21 & .17 \\
\hline Flight & .12 & .07 \\
\hline Landing & .12 & .163 \\
\hline Total time of the skill & .94 & 1.013 \\
\hline
\end{tabular}

Table (1) shows that although the total time taken by the high level fencer $(.94 \mathrm{~s})$ is very close to the time taken by the normal level fencer $(1.013 \mathrm{~s})$, there are still differences in the time taken in different phases.

Table (2)

Horizontal speed and velocity of the Flèche skill in the on guard phase for high level and normal level fencers

\begin{tabular}{|l|l|l|l|l|}
\hline \multirow{2}{*}{ Anatomy parts } & \multicolumn{2}{l|}{ Horizontal speed } & Horizontal velocity \\
\cline { 2 - 5 } & High level & Normal level & High level & Normal level \\
\hline Fingers & 80.1 & 0 & 965.6 & 732.1 \\
\hline Wrist & 47.9 & 32.7 & 482.7 & 395.4 \\
\hline Elbow & 65.8 & 48.9 & -240.2 & -214.5 \\
\hline Shoulder & 16.4 & 14.8 & -240.3 & -235.4 \\
\hline Thigh & 15.9 & 12.7 & 482.7 & 395.4 \\
\hline Knee & 47.5 & 32.1 & 1691.9 & 964.8 \\
\hline Ankle & -16.2 & 14.3 & 241.3 & 213.9 \\
\hline
\end{tabular}

Table (2) compares the values of horizontal speed and velocity in the two levels in the on guard phase 
Table (3)

Horizontal speed and velocity of the Flèche skill in the losing balance phase for high level and normal level fencers

\begin{tabular}{|l|l|l|l|l|}
\hline \multirow{2}{*}{ Anatomy parts } & \multicolumn{2}{l|}{ Horizontal speed } & Horizontal velocity \\
\cline { 2 - 5 } & High level & Normal level & High level & Normal level \\
\hline Fingers & 323.2 & -154.7 & -484.7 & -8842.3 \\
\hline Wrist & 259.9 & 1030.9 & -1449.1 & -8843.4 \\
\hline Elbow & 309.1 & 1267.3 & 4350.8 & 7735.9 \\
\hline Shoulder & 256.4 & 1276.9 & 485.3 & -7366.9 \\
\hline Thigh & 162.1 & 635.8 & -2655.8 & 4789.8 \\
\hline Knee & 47.6 & 415.7 & 1932,6 & 5527.5 \\
\hline Ankle & - & 97.8 & -5154. & -2213.0 \\
\hline
\end{tabular}

Table (3) compares the values of horizontal speed and velocity in the two levels in the losing balance phase

Table (4)

Horizontal speed and velocity of the Flèche skill in the flight phase for high level and normal level fencers

\begin{tabular}{|l|l|l|l|l|}
\hline \multirow{2}{*}{ Anatomy parts } & \multicolumn{2}{l|}{ Horizontal speed } & Horizontal velocity \\
\cline { 2 - 5 } & High level & Normal level & High level & Normal level \\
\hline Fingers & 288.9 & 144.7 & - & -364.8 \\
\hline Wrist & 323.2 & 128.2 & -1691.2 & 738.6 \\
\hline Elbow & 302.6 & 179.1 & 1454.0 & 738.6 \\
\hline Shoulder & 334.8 & 195.6 & -2176.5 & 1101.5 \\
\hline Thigh & 377.0 & 179.1 & 969.6 & -1101.5 \\
\hline Knee & 289.0 & 364.8 & 485.3 & 2577.8 \\
\hline Ankle & 173.7 & 92.8 & 2176.5 & 2213.0 \\
\hline
\end{tabular}

Table (4) compares the values of horizontal speed and velocity in the two levels in the flight phase. 
Table (5)

Horizontal speed and velocity of the Flèche skill in the landing phase for high level and normal level fencers

\begin{tabular}{|l|l|l|l|l|}
\hline \multirow{2}{*}{ Anatomy parts } & \multicolumn{2}{|l|}{ Horizontal speed } & Horizontal velocity \\
\cline { 2 - 5 } & High level & Normal level & High level & Normal level \\
\hline Fingers & 131.7 & 182.2 & -453.8 & -2230.1 \\
\hline Wrist & 265.2 & 201.2 & 735.4 & -1115.0 \\
\hline Elbow & 210.9 & 265.4 & -3334.8 & -348.6 \\
\hline Shoulder & 492.0 & 395.0 & -1612.9 & 1115.0 \\
\hline Thigh & -259. & 265.4 & 1278.0 & 2230.1 \\
\hline Knee & 348.3 & 348.6 & 2519.6 & 1094.2 \\
\hline Ankle & 396.7 & 339.1 & 2234.8 & 4460.2 \\
\hline
\end{tabular}

Table (5) compares the values of horizontal speed and velocity in the two levels in the landing phase.

Table (6)

Vertical speed and velocity of the Flèche skill in the on guard phase for high level and normal level fencers

\begin{tabular}{|l|l|l|l|l|}
\hline \multirow{2}{*}{ Anatomy parts } & \multicolumn{2}{|l|}{ vertical speed } & \multicolumn{2}{l|}{ vertical velocity } \\
\cline { 2 - 5 } & High level & Normal level & High level & Normal level \\
\hline Fingers & 15.9 & 18.7 & 1932.7 & 1978.4 \\
\hline Wrist & 15.9 & 18.7 & 965.8 & 987.3 \\
\hline Elbow & 15.9 & 18.7 & 239.3 & 283.6 \\
\hline Shoulder & -159.9 & -166.4 & -1449.2 & -1503.4 \\
\hline Thigh & 15.9 & 18.7 & 719.7 & 783.3 \\
\hline Knee & 15.9 & 18.7 & -718.6 & -794.5 \\
\hline Ankle & 15.9 & 18.7 & -719.5 & -782.0 \\
\hline
\end{tabular}

Table (6) compares the values of vertical speed and velocity in the two levels in the on guard phase 
Table (7)

Vertical speed and velocity of the Flèche skill in the losing balance phase for high level and normal level fencers

\begin{tabular}{|l|l|l|l|l|}
\hline \multirow{2}{*}{ Anatomy parts } & \multicolumn{2}{|l|}{ vertical speed } & \multicolumn{2}{l|}{ vertical velocity } \\
\cline { 2 - 5 } & High level & Normal level 1 & High level & Normal level \\
\hline Fingers & 15.9 & 186.9 & 271.4 & -3305.1 \\
\hline Wrist & 31.4 & 309.1 & 271.4 & -2586.7 \\
\hline Elbow & 31.4 & 382.9 & -735.7 & -746.3 \\
\hline Shoulder & - & -76.5 & 996.6 & -746.3 \\
\hline Thigh & 15.9 & 27.9 & -1198.8 & -1483.7 \\
\hline Knee & 15.9 & -76.5 & 996.6 & -3674.8 \\
\hline Ankle & 15.9 & 76.5 & 735.7 & -746.3 \\
\hline
\end{tabular}

Table (7) compares the values of vertical speed and velocity in the two levels in the losing balance phase.

Table (8)

Vertical speed and velocity of the Flèche skill in the flight phase for high level and normal level fencers

\begin{tabular}{|l|l|l|l|l|}
\hline \multirow{2}{*}{ Anatomy parts } & \multicolumn{2}{|l|}{ vertical speed } & vertical velocity \\
\cline { 2 - 5 } & High level & Normal level 1 & High level & Normal level \\
\hline Fingers & 76.7 & 146.3 & $-1197,5$ & 1461.3 \\
\hline Wrist & 76.7 & 169.8 & -1937.8 & 1069.8 \\
\hline Elbow & 31.9 & 129.8 & 473.2 & 359.6 \\
\hline Shoulder & 15.9 & 129.8 & -231.4 & 759.6 \\
\hline Thigh & -31.9 & -169.8 & -2648.5 & 359.6 \\
\hline Knee & 89.5 & -89.6 & -2405.3 & -2209.1 \\
\hline Ankle & 287.9 & 18.4 & -2405.3 & 1452.7 \\
\hline
\end{tabular}

Table (8) compares the values of vertical speed and velocity in the two levels in the flight phase 
Table (9)

Vertical speed and velocity of the Flèche skill in the landing phase for high level and normal level fencers

\begin{tabular}{|l|l|l|l|l|}
\hline \multirow{2}{*}{ Anatomy parts } & \multicolumn{2}{|l|}{ vertical speed } & vertical velocity \\
\cline { 2 - 5 } & High level & Normal level 1 & High level & Normal level \\
\hline Fingers & 72.5 & -726.4 & 269.7 & - \\
\hline Wrist & 15,9 & -230.9 & 246.5 & -735.7 \\
\hline Elbow & 142.3 & -965.7 & 145.6 & -367.6 \\
\hline Shoulder & 142.3 & -230.9 & 72.9 & -2575.9 \\
\hline Thigh & -131.7 & -1931.7 & 48.9 & 3303.6 \\
\hline Knee & -229.6 & -1931.7 & -48.9 & - \\
\hline ankle & 142.3 & -4343.4 & 173.6 & 1475.3 \\
\hline
\end{tabular}

Table (9) compares the values of vertical speed and velocity in the two levels in the landing phase

Table (10)

Speed achieved of the body center of gravity in phases of performing the Flèche skill by high level and normal level fencers

\begin{tabular}{|l|l|l|}
\hline \multirow{2}{*}{ Performance phase } & Speed achieved \\
\cline { 2 - 3 } & High level fencer & Normal level fencer \\
\hline On guard & 72.5 & 77.0 \\
\hline Losing balance & 41.3 & 37.3 \\
\hline Flight & 320.8 & 303.0 \\
\hline Landing & 291.5 & 116.9 \\
\hline
\end{tabular}

Table (10) compares the values of speed achieved by the body center of gravity in the different phases of performing the Flèche skill.

Table (11)

Angular speed of the body center of gravity in phases of performing the Flèche skill by high level and normal level fencers

\begin{tabular}{|l|l|l|}
\hline \multirow{2}{*}{ Performance phase } & Angular speed \\
\cline { 2 - 3 } & High level fencer & Normal level fencer \\
\hline On guard & -2.915 & 1.768 \\
\hline Losing balance & 1.574 & -3.372 \\
\hline Flight & -4.553 & -3.879 \\
\hline Landing & -6.397 & 4.156 \\
\hline
\end{tabular}

Table (11) compares the values of angular speed of the body center of gravity in the different phases of performing the Flèche skill. 
Table (12)

Angular velocity of the body center of gravity in phases of performing the Flèche skill by high level and normal level fencers

\begin{tabular}{|l|l|l|}
\hline \multirow{2}{*}{ Performance phase } & Angular velocity \\
\cline { 2 - 3 } & High level fencer & Normal level fencer \\
\hline On guard & -2.915 & 1.768 \\
\hline Losing balance & 1.574 & -3.372 \\
\hline Flight & -4.553 & -3.879 \\
\hline Landing & -6.397 & 4.156 \\
\hline
\end{tabular}

Table (12) compares the values of angular velocity of the body center of gravity in the different phases of performing the Flèche skill.

\section{Discussion of the results}

Table (1) shows that although the total time taken by the high level fencer (.94 s) is very close to the time taken by the normal level fencer $(1.013 \mathrm{~s})$, there are still differences in the time taken in different phases. While the on guard phase took the high level fencer $.49 \mathrm{~s}$, the normal fencer took .61 s to do it. This may be due to the fact that the fencer should fully extend his/her arm in the on guard position because the blade is in a horizontal position. This result agrees with the findings of $\mathrm{L}$. R. William, and A. W. Almsley (2000), i.e., the reaction time of skillful fencers was shorter, leading to a statistically significant shorter total time of response.

The losing balance phase took the high level fencer longer time to finish $(.21 \mathrm{~s})$ than the normal fencer (.17). As shown in Tables (3) and (7), values of the horizontal and vertical speeds of the ankle in normal level fencer (97.7 and $76.5 \mathrm{~cm} / \mathrm{s}$ ) were higher than their counterparts in high level fencer $(0$ and $15.9 \mathrm{~cm} / \mathrm{s})$. This also agrees with findings of the previous study according to which movement time after reaction time was shorter in skillful fencers.

The flight time was longer in the high level fencer $(.12 \mathrm{~s})$ than in the normal level fencer $(.07 \mathrm{~s})$. This complies with the data in Table (10) where the speed achieved was $320.8 \mathrm{~cm} / \mathrm{s}$ for the high level fencer and $-303 \mathrm{~cm} / \mathrm{s}$ for normal level fencer. In Table (4), the horizontal speed of the thigh joint was $-377.0 \mathrm{~cm} / \mathrm{s}$ for the normal level fencer, and $179.1 \mathrm{~cm} / \mathrm{s}$ for the high level fencer. This agrees with the mechanical relationship, i.e., flight time increases with the increase in horizontal speed in the flight phase of the skill. Although the total time taken by the high level fencer is very close to the total time taken by the normal level fencer, there are still differences in details of the skill phases, and the time variable plays an important role here.

According to table (2), illustrating values of the kinematical variables addressed in this paper, the high level fencer recorded the highest values of the horizontal speed of the elbow of the working arm in the on guard phase $(65.8 \mathrm{~cm} / \mathrm{s})$ , compared to the normal level fencer who recorded $48.9 \mathrm{~cm} / \mathrm{s}$. The value for the horizontal speed of the fingers was also higher in the high level fencer $(80.1 \mathrm{~cm} / \mathrm{s})$, compared to that of the normal level fencer $(0.0 \mathrm{~cm} / \mathrm{s})$. This is attributed to the fact that the aim of the Flèche skill is to achieve the touch in the shortest time possible, while applying the principle of surprise. L. W. (1996)(15) stated that performance must combine speed with the accuracy of attack, bearing in mind the relationship between accuracy and speed. In order to achieve this, rules of mechanics must be appropriately complied with.

Based on the previous discussion, horizontal parameters were more important than vertical parameters. The high level fencer achieved a higher horizontal speed of the working arm than the normal level fencer who recorded higher vertical speeds (which are not required in view of the direction of movement).

Regarding the losing balance phase, tables (3) and (7) indicate a great and sharp increase in the 
kinematical variables of horizontal and vertical speeds in normal level fencer, compared to the high level fencer, sometimes reaching double the value.

The kinematical parameters of the flight phase showed higher horizontal speed values in most of the anatomical points measured in the high level fencer than in the normal level fencer, and lower vertical speeds in the high level fencer, compared to the normal level fencer. The time taken by the high level fencer was $.21 \mathrm{~s}$, compared to the time taken by the normal level fencer, which was .17 s. This means that performance of the Flèche skill does not require increasing the flight time, but a speedy movement forwards where the body movement is not affected by gravity, regardless of the air resistance.

Based on the previous discussion, horizontal parameters were more important than vertical parameters. Tables (5) and (9) show that the high level fencer achieved higher horizontal and vertical speeds in the landing phase, compared to the normal level fencer. This means higher values of the speed achieved, a fact supported by results of Tables (10) and (1), where the high level fencer achieved a shorter time of landing than the normal level fencer, and where the high level fencer recorded higher values of the speed achieved by the body center of gravity, compared to the normal level fencer. This may be attributed to the fact that the high level fencer has more experience and more training years, leading to a better performance of the skill. This agrees with the findings of Osama Abdel Rahman (2008)(2) who suggested that distance, timing and rhythm are major factors that contribute to a successful attack (2: 196).

The values for the angular speed in the on guard phase in Table (11) were higher in the high level fencer compared to the normal level fencer, thus affecting the speed of the whole body, so that the speed achieved by the body center of gravity was $72.5 \mathrm{~cm} / \mathrm{s}$ in the high level fencer and $77.0 \mathrm{~cm} / \mathrm{s}$ in the normal level fencer.

It was also noted that the high level fencer achieved a higher speed of the body center of gravity, compared to the normal level fencer, which was obvious in the flight phase, because the speed achieved depends on the speed of the working joints, a fact supported by the data in Table (10). Such an increase in the kinematical variable leads to an improvement of the performance of the Flèche skill in the on guard and flight phases. Thus the hypothesis of the research is proved to be true.

\section{Conclusions}

Although the time structure of the skill as a whole is almost the same, there are differences in details of each phase.

The on guard phase: regarding the values for speeds and velocities, the high level fencer achieved a higher horizontal speed of the working arm than the normal level fencer who recorded higher vertical speeds (which are not required in view of the direction of movement).

The losing balance phase: the values for horizontal and vertical speeds are higher in the normal level fencer than in the high level fencer.

The flight phase: the high level fencer achieved higher values for the horizontal speeds and velocities of the arm and leg than their vertical counterparts.

The landing phase: there was an increase in the values for the kinematical variables of the center of gravity in the high level and normal level fencers in the losing balance, flight and landing phases.

\section{Recommendations}

- More attention should be given to the kinematical analysis in evaluating the kinetic performance of all types of fencing and of sport activities in general.

- The kinematical variables that help improve the performance level of fencers should be developed.

- Focusing on the horizontal speed of the fencer to achieve the aim of the skill.

\section{References}

1- Ehab Mohamed Abdel Basir (2005): Biomechanic Analysis and Integration in Theory and Practice in Sport. AlMottaheda for Printing and Photocpying, Port Said.

2- Osama Abdel Rahman (2008): the Basic Principles of Fencing (Part 1), $2^{\text {nd }}$ edition. 
3- Gamal Zaher Ibrahim (1994): The Relationship between the Kinematical Characteristics of the Flèche Skill and the Reaction Speed and Explosive Power in Fencers, unpublished Ph. D. dissertation, Faculty of Physical Education, Port Said, Suez Canal University.

4-

Designing a Suggested Equipment for Measuring Accuracy and Kinetic Reaction Speed in Foil Fencers, Journal of the Faculty of Physical Education, Tanta University.

5- Gamal Abdel Hamid Abdin (1989) Foundations of Fencing, Dar El-Maaref, Egypt.

6- Gamal Mohamed Alaa el Din (1981): A Modified Method to Use Television Shooting as a Rapid Measurement Technique in the Simple Qualitative and Quantitative Analysis of Sport Movement. Paper published in the Second Scientific Conference of Sports Studies and Research, Faculty of Physical Education, Helwan University.

$7-$

Movement System and the Controlling Mechanisms, Nazaryat Wa Tatbiqat Journal of the Faculty of Physical Education for Boys, Alexandria University, No 6 Alexandria.

8-

Lab Studies in the Biomechanics of Sport Movements, Dar El-Maaref, Cairo.

9- Sameh Saad Bahnasy (2003): The Effect of a Training Programme to develop Some Physical Characteristics of the Armed Hand on the Accuracy and Speed of the Counter Attack in Foil Fencing, Ph. D. dissertation, Faculty of Physical Education, Port Said, Suez Canal University.

10- Sameh Mohamed Magdy (2007): The Effect of a Training Programme of
Some Tactical Variables on the Results of the National Fencing Team Matches, $\mathrm{Ph}$. D. dissertation, Faculty of Physical Education, Mansoura University.

11- Mahrousa Aly Hassan (1999): A Comparative Study of Some Kinematical Variables of the Flèche Skill in Saber Fencers, the Third Scientific Conference of Sports Studies, Faculty of Physical Education for Girls, Alexandria University.

12- Essam el Din Metwally Aly (1987): The Kinematical Analysis of the performing the Straight Attack in Foil Fencing, unpublished Master thesis, Faculty of Physical Education for Girls, Helwan University.

13- Abbas Abdel Fattah Al-Ramly (1981): Fencing \& Foil Fencing, Dar Al-Fikr Al-Araby.

14- D, Gordon E, R Brtson, Gary Kamen, Goseph Hamil (2004): Research methods in Biomechanics, Human Kinetics Publisher: U. S. A.

15- Li, W. (1996): on Quickness, Ferocity, Accuracy \& and Change of Epee Fencing and their relationships, Journal of Shanghai Physical Education.

16- Said, E. A. Hassan , Jurgen Klauck (1999): Kinematics of Lower and Upper Extremities Motions during the Fencing Lunge "results and training implication", Deutsch Sport Hochschule, Germany.

17- Sander. L, Le Fevers Victor (1999): Relationships between Components of Speed, Accuracy \& Fencing Success, the Annual Meeting of the American Alliance for health, physical and recreation.

18- S. Zilagyi, T (1990): Kinematic Parameteres of Fencing, LVNG Hungarian University of Briame Chancs, Budapest. 